\title{
OPTIMALISASI PENDIDIKAN KEWARGANEGARAAN DALAM MENGATASI PERILAKU BULLYING SISWA SEKOLAH DASAR
}

\author{
Oleh: \\ Usmaedi $^{1}$, Sapriya ${ }^{2}$, dan Eka Nurul Mualimah ${ }^{3}$ \\ ${ }^{1}$ Universitas Pendidikan Indonesia; usmaedichalid@upi.edu \\ ${ }^{2}$ Universitas Pendidikan Indonesia; sapriya@upi.edu \\ ${ }^{3}$ STKIP Setiabudhi; Email : e_frisca@yahoo.com
}

\begin{abstract}
ABSTRAK: Penelitian ini menyajikan tinjauan literatur tentang optimalisasi pendidikan kewarganegaraan dalam mengatasi perilaku bullying yang terjadi di sekolah dasar. Pendidikan Kewarganegaraan (PKn) di sekolah dasar memiliki arti penting bagi siswa pada pembentukan pribadi warga negara yang memahami dan mampu melaksanakan hakhak dan kewajiban untuk menjadi warga negara Indonesia yang cerdas, terampil dan berkarakter yang diamanatkan dalam Pancasila dan Undang-Undang Dasar 1945. Bulliying adalah suatu bentuk kekerasan anak (child abuse) yang dilakukan teman sebaya kepada seseorang (anak) yang lebih 'rendah' atau lebih lemah untuk mendapatkan keuntungan atau kepuasan tertentu. Aksi ini dilakukan secara langsung oleh seseorang atau sekelompok orang lebih kuat, tidak bertanggung jawab, biasanya berulang dan dilakukan dengan perasaan senang. Metode Penelitian dilakukan dengan desain kualitatif. Teknik pengumpulan data melalui kajian literatur dilakukan dengan studi dokumen. Kajian literatur adalah analisis, evaluasi kritis dan sintesis pengetahuan yang relevan dengan masalah yang ingin disampaikan. Berdasarkan hal tersebut dapat disimpulkan bahwa bentuk bullying yang paling sering dialami adalah bullying verbal, fisik, dan relasional. Bentuk bullying verbal berupa memanggil dengan panggilan yang buruk, membentak, mengancam. Bentuk bullying Fisik berupa mendorong, memukul, berkelahi, mengambil barang, mengunci di kamar mandi. Sementara bentuk bullying relasional adalah mengucilkan dan memfitnah. Pendidikan Kewarganegaraan di Sekolah Dasar, diharapkan mampu membentuk karakter murid dan mampu membantu murid memahami dan mampu melaksanakan hak-hak dan kewajibannya untuk menjadi warga negara yang baik, cerdas, terampil, dan bertanggung jawab. Peran penting untuk mengoptimalisasi tindakan bullying adanya peran dari lingkungannya baik di sekolah, keluarga maupun masyarakat agar perilaku bullying tidak berulang terjadi.
\end{abstract}

\section{KATA KUNCI: Bullying, Pendidikan Kewarganegaraan, Siswa Sekolah Dasar}

ABSTRACT: This study presents a literature review on optimizing citizenship education in addressing bullying behaviors that occur in primary schools. Citizenship Education $(\mathrm{PKn})$ in elementary schools has an important meaning for students on the personal formation of citizens who understand and are able to carry out the rights and obligations to become intelligent, skilled and characterful Indonesian citizens mandated in Pancasila and the 1945 Constitution. Bulliying is a form of child abuse that peers do to someone (child) who is 'inferior' or weaker to gain certain benefits or satisfaction. This action is performed directly by a person or a group of people stronger, irresponsible, usually 
repetitive and done with a feeling of pleasure. Research methods are conducted with qualitative design. Data collection techniques through literature studies are conducted with document studies. Literature studies are analysis, critical evaluation and synthesis of knowledge relevant to the problem to be addressed. Based on this, it can be concluded that the most common form of bullying is verbal, physical, and relational bullying. A form of verbal bullying is calling with a bad call, yelling, threatening. Physical forms of bullying in the form of pushing, hitting, fighting, picking up things, locking in the bathroom. While a form of relational bullying is exclusion and slander. Citizenship Education in Elementary School, is expected to be able to shape the character of students and be able to help students understand and be able to carry out their rights and obligations to become good, intelligent, skilled, and responsible citizens. An important role to optimize the act of bullying is the role of the environment both in school, family and community so that bullying behavior does not recur.

KEYWORDS: Bullying, Civics Education, Elementary School

\section{PENDAHULUAN}

Pendidikan memiliki peran penting dalam perkembangan pribadi seseorang. Seseorang dapat menjadi pribadi yang optimal tentunya dengan dukungan dari segala aspek yang mampu mengoptimalkan semua komponen perkembangan baik kognitif, afektif maupun psikomotorik.

Pendidikan diakui sebagai komponen yang paling menentukan kemajuan suatu bangsa. Oleh karena itu salah satu upaya yang terus dikembangkan oleh sebuah bangsa yang maju adalah memposisikan pendidikan sebagai suatu hal yang sangat prioritas. Pendidikan merupakan kebudayaan yang menjadi salah satu bidang yang sangat strategis dalam membina manusia dan pembangunan bangsa. Pembangunan kebudayaan berfungsi untuk meningkatkan kualitas sumber daya manusia (SDM) dalam mewujudkan citacita bangsa yang hendak dicapai dalam ruang lingkup nasional dan internasional untuk menghadapi tantangan masa kini dan masa yang akan datang.

Dalam menghadapi tantangan dan perkembangan zaman yang berkembang sangat pesat seperti sekarang ini, pendidikan dituntut untuk menyelenggarakan secara sistematis, efektif, berbobot dan menyenangkan, sehingga proses yang terjadi di dalamnya dapat menjadi sumbangan yang besar bagi kehidupan sosial masyarakat. Dalam kontek ini, sekolah dituntut untuk mempersiapkan siswa dengan berbagai ilmu dan keterampilan, agar mereka mampu berperan dalam kehidupan di masyarakat. Oleh karena itu, lembaga pendidikan perlu secara terus-menerus untuk meningkatkan mutu pendidikan sebagai konsekuensi dari adanya tuntutan perkembangan zaman. Pada saat ini berbagai upaya telah dilakukan oleh lembaga pendidikan untuk memenuhi kebutuhan dan harapan masyarakat. Oleh karena itu masyarakat secara langsung atau tidak langsung, turut menentukan 
corak, jenis, kualitas dan kuantitas lembaga pendidikan.

Guru merupakan ujung tombak dalam mencetak generasi yang cerdas, bertanggung jawab, demokratis, dan berakhlak mulia. Oleh karena itu dalam kontek pembelajaran, maka seorang guru haruslah pandai dalam memilih media pembelajaran, sehingga terwujudlah suasana belajar yang efektif, menarik dan menyenangkan. Berkaitan dengan proses belajar mengajar siswa, motivasi belajar sangatlah diperlukan. Diyakini bahwa hasil belajar akan meningkat jika siswa mempunyai motivasi belajar yang kuat. Siswa pada dasarnya termotivasi untuk melakukan suatu aktivitas untuk dirinya sendiri karena ingin mendapatkan kesenangan dari pelajaran, atau merasa kebutuhannya terpenuhi.

Pendidikan di Indonesia diharapkan dapat mempersiapkan siswa menjadi warga Negara yang memiliki komitmen kuat dan konsisten untuk mempertahankan Negara Kesatuan Republik Indonesia. Komitmen yang kuat dan konsisten perlu ditingkatkan untuk memberikan pemahaman yang mendalam tentang Negara Kesatuan Republik Indonesia. Pendidikan Kewarganegaraan (Citizenship Education) merupakan mata pelajaran yang memfokuskan pada pembentukan diri yang beragam dari segi agama, sosio-kultural, bahasa, usia, dan suku bangsa.

Hakikat pendidikan kewarganegaraan merupakan sarana pembelajaran yang bersumber dari nilainilai Pancasila sebagai kepribadian bangsa. Hal ini diperlukan agar Bangsa Indonesia memiliki kesadaran untuk mencintai tanah air serta memiliki watak, sifat dan karakter yang sesuai dengan nilai Pancasila (Vanya Karunia Mulia Putri, 2021).

Pendidikan kewarganegaraan pada hakikatnya merupakan pendidikan yang mengarah pada terbentuknya warga negara yang baik dan bertanggung jawab berdasarkan nilai-nilai dan dasar negara Pancasila. Secara konseptualepistemologis, pendidikan Pancasila dapat dilihat sebagai suatu integrated knowledge system (Hartonian, 1992 dalam Udin S. Winataputra, 2001), yang memiliki misi menumbuhkan potensi peserta didik agar memiliki 'civic intelligence' dan 'civic participation' serta 'civic responsibility' sebagai warga negara Indonesia dalam konteks watak dan peradaban bangsa Indonesia yang ber-Pancasila (Udin S. Winataputra, 2001).

Pendidikan Kewarganegaraan (PKn) di sekolah dasar memiliki arti penting bagi siswa pada pembentukan pribadi warga negara yang memahami dan mampu melaksanakan hak-hak dan kewajiban untuk menjadi warga negara Indonesia yang cerdas, terampil dan berkarakter yang diamanatkan dalam Pancasila dan Undang-Undang Dasar 1945 (Depdiknas, 2006).

Perilaku menyimpang anak banyak mendapat perhatian, khususnya kasus yang terjadi pada anak Sekolah Dasar. Bentuk-bentuk intimidasi yang diperoleh di antaranya pemalakan, pengucilan diri, merasa terancam, mendapatkan banyak gangguan secara fisik, verbal, dan pelecehan seksual.

Bulliying adalah suatu bentuk kekerasan anak (child abuse) yang dilakukan teman sebaya kepada seeorang 
(anak) yang lebih 'rendah' atau lebih lemah untuk mendapatkan keuntungan atau kepuasan tertentu. Budaya bulliying (kekerasan) atas nama senioritas masih terus terjadi di kalangan peserta didik di sekolah dasar, biasanya bulliying terjadi berulang kali, bahkan ada yang dilakukan secara terencana.

Kasus yang dewasa ini hangat diperbincangkan mengenai diskriminasi pendidikan. Bullying menjadi isu kritis dikarenakan tidak hanya berhenti di usia anak-anak. Faktor yang paling beresiko untuk di bully kembali terjadi pada jenjang yang lebih tinggi atau dewasa, karena sebelumnya seseorang pernah menjadi korban bully (Andersen, dkk, 2015:1). Data dari CDC (Centers for Disease Control and Prevention) di tahun 2013 bahwa 19.6\% dilaporkan telah dibully di lingkungan sekolah, dan 14,8\% siswa dibully secara elektronik, di samping kekerasan seperti tawuran pelajar, kepemilikan senjata, dan berhenti bersekolah akibat alasan keamanan. Survey yang dilakukan di Belanda terhadap 6379 siswa sekolah usia 5-6 tahun diperoleh data bahwa sepertiga anak terlibat di bullying, sebanyak $17 \%$ merupakan pelaku, 13\% merupakan korban bully (Jensen, 2012).

Indonesia juga tidak lepas dari gencarnya pemberitaan kasus bullying. Berdasarkan data dari Komisi Perlindungan Anak Indonesia (KPAI), kasus bullying di sekolah menduduki peringkat paling atas terkait pengaduan masyarakat ke KPAI di sektor pendidikan. Data tahun 2011 sampai dengan 2014 mengungkap 369 pengaduan terkait masalah tersebut, sekitar $25 \%$ dari total pengaduan di bidang pendidikan sebanyak 1.480 kasus. Bullying yang disebut KPAI sebagai bentuk kekerasan di sekolah mengalahkan tawuran pelajar, diskriminasi pendidikan, ataupun pengaduan pungutan liar (Republika, 2014). Kasus demi kasus muncul dan menimbulkan berbagai pertanyaan dihubungkan dalam dunia pendidikan, khususnya mengenai pendidikan kewarganegaraan diwujudkan dengan dengan nilai-nilai kebaikan pada diri seseorang. Tulisan ini bertujuan untuk memaparkan hal-hal yang mampu mencegah, mengurangi, atau menghentikan perilaku bullying yang marak terjadi terutama di lingkungan sekolah. Kajian ini memberikan gambaran tentang upaya-upaya yang dapat dilakukan baik dari seluruh pihak untuk dapat memberikan upaya solutif demi tercapainya tujuan pendidikan.

Guna menanggulangi permasalahan tersebut pendidikan kewarganegaraan merupakan salah satu cara atau sarana untuk memperbaiki moral siswa khususnya di sekolah dasar. Disinilah peran pendidik sangat diperlukan untuk mengajarkan dan menerapkan pendidikan kewarganegaraan kepada peserta didik.

\section{METODE}

Penelitian dilakukan dengan desain kualitatif. Teknik pengumpulan data melalui kajian literatur dilakukan dengan studi dokumen. Kajian literatur adalah analisis, evaluasi kritis dan sintesis pengetahuan yang relevan dengan masalah yang ingin disampaikan (Hart, 2018). 


\section{HASIL DAN PEMBAHASAN}

Dalam Kurikulum 2013, Kompetensi Inti (KI) dan kompentesi dasar (KD) mata pelajaran PKn, mengikuti Gerhard Himmelmann (2013), mengubah paradigma pendidikan kewarganegaraan yang semula berfokus kepada program pengajaran dan transfer pengetahuan kewarganegaraan menjadi pendekatan yang menekankan sikapsikap personal individual, moral dan perilaku sosial sebagaimana disposisi dan nilai-nilai bersama dari warga negara dalam kehidupan bersama yang menghargai hak-hak asasi manusia dan demokrasi di dunia yang penuh konflik.

Secara umum, terdapat beberapa kategori dalam perilaku bullying yaitu pelaku, korban dan saksi/penonton bullying. Ketiganya memiliki karakteristik dan implikasi yang berbedabeda namun saling terkait. Hal mendasar yang menjadi pertimbangan keterkaitan adalah semuanya terjadi dalam sebuah sistem. Faktor penyebab bullying umumnya orang melakukan bullying karena merasa tertekan, terancam, terhina, dendam, dan sebagainya. Penyebab bullying berakar dari keadaan lingkungan yang membentuk kepribadiannya menjadi agresif dan kurang mampu mengendalikan emosi.

Rianuskina (dalam Ehan, 2013) mengelompokkan bullying ke dalam lima kategori yaitu:

1) Kontak fisik langsung (memukul, mendorong, mencubit, juga termasuk memeras dan merusak barang-barang yang dimiliki orang lain).

2) Kontak verbal langsung (mengancam, mempermalukan, merendahkan, mengganggu, memberi pannggilan nama, sarkasme, merendahkan, mencela dan mengejek, mengintimidasi, mengejek, dan menyebarkan gosip).

3) Perilaku nonverbal langsung (melihat dengan sinis, menjulurkan lidah, menampilkan ekspresi muka yang merendahkan, mengejek, atau mengancam, biasanya disertai oleh bullying fisik atau verbal).

4) Perilaku non verbal tidak langsung (mendiamkan seseorang, memanipulasi persahabatan sehingga menjadi retak, sengaja mengucilkan atau mengabaikan, mengirimkan surat kaleng).

5) Pelecehan seksual (kadang dikategorikan perilaku agresi fisik atau verbal).

Cara yang dipandang tepat dalam menangani masalah bullying pada anak sekolah dasar yaitu ditanamkan kecerdasan emosional sejak dini. Penerapan kecerdasan emosional yang dilakukan dapat mencegah timbulnya bullying. Para kepala sekolah, guru, orang tua, dan staf administrasi hendaknya menerapkan kepemimpinan moral (Akbar, 2011:22). Kepemimpinan moral diwujudkan berupa keteladanan dari kepribadian seorang pemimpin yang diyakini melalui ucapan, sikap, dan perbuatan.

Peran penting keluarga terutama orang tua mampu menciptakan komunikasi baik dengan membekali anak dengan beragam pemahaman agama untuk masuk dalam dunia religius anak sehingga penanaman akhlakul karimah yang selalu ditanamkan dalam keluarga akan berdampak pada lingkungan di 
mana anak berada. Menjadikan orang tua sebagai suri tauladan anak akan menciptakan perilaku positif demi kemajuan anak untuk mewujudkan pendidikan karakter anak khususnya pengaruh bullying di sekitar anak.

Optimalisasi pihak sekolah dalam mencegah tindakan bullying akan berdampak positif bagi siswa dengan dilakukan berbagai cara kreatif di antaranya melakukan kegiatan sosial dan meningkatkan kreativitas anak melalui hal-hal yang mendukung potensi dan bakatnya untuk ditingkatkan melalui serangkaian kegiatan positif. Pembelajaran terintegrasi mampu memberikan pengalaman belajar yang bermakna kepada peserta didik. Salah satunya menggunakan pembelajaran tematik. Tema-tema yang digunakan dalam pendidikan karakter yang komprehensif diitegrasikan dalam pembelajaran dan pengembangan kultur sekolah. Dengan demikian, diharapkan integrasi nilai-nilai dapat berlansung secara efektif dan bermakna.

Penetapan kebijakan terkait internalisasi nilai yaitu dengan mendukung kegiatan hidden curriculum seperti kegiatan sosial dan budaya, waktu istirahat, kegiatan olahraga, dan nilainilai yang diterapkan dalam perayaan hari-hari keagamaan di sekolah. Hidden curriculum mengindikasikan bahwa tingkah laku guru dan staf melalui pendekatan dialog untuk siswa, pendidikan yang kooperatif dan kompetitif yang sehat, nilai dan lingkungan belajar yang diciptakan di sekolah akan mempengaruhi tingkah laku dan sikap siswa saat berinteraksi di sekolah (Çubukçu, 2012).
Peran sekolah menjadi hal strategis dalam menanggulangi permasalah bullying. Hal yang dapat dioptimalkan yaitu pengembangan kultur sekolah yang merupakan bagian sistem sekolah (Wiyani, 2013). Dalam hal itu, seluruh warga sekolah baik guru, siswa, staff, dan kepala sekolah dapat dengan terstruktur bekerja sama dalam pengembangan budaya sekolah berdasarkan nilai-nilai yang dikembangkan di lembaga pendidikan tersebut.

Pendidikan kewarganegaraan bertujuan agar siswa dapat berpikir secara kritis, kreatif cerdas dan bertanggung jawab, sehingga Pendidikan kewarganegaraan tidak hanya mengedepankan kemampuan intelektual saja namun juga mengedepankan moralitas peserta didik. Pendidikan kewarganegaraan merupakan Pendidikan yang berperan penting untuk membentuk kepribadian bagi siswa Sekolah Dasar. Hal ini disebabkan Pendidikan kewarganegaraan mempelajari tentang bagaimana siswa Sekolah Dasar untuk menjadi warga negara yang baik dan benar. Pendidikan kewarganegaraan menjadi mata pelajaran yang sangat wajib untuk dipelajari dari tingkat dasar sampai perguruan tinggi, karena begitu pentingnya dipelajari bagi penerus bangsa. Pendidikan kewarganegaraan mengajarkan bagaimana menciptakan kerukunan di lingkungan sekolah.

Sejalan dengan tujuan Pendidikan kewarganegaraan yaitu untuk mengetahui dan memahami isi dan makna yang terkandung didalam Pancasila dan UUD 1945 atau dengan kata lain untuk menjadi warga negara yang baik berdasarkan falsafah negara dan Undang-Undang 
Dasar 1945 dan dengan demikian Pendidikan kewarganegaraan adalah salah satu upaya Pendidikan yang menyangkut pembentukan dan perkembangan pribadi dan anak didik atau dengan kata lain dengan merupakan salah satu cara untuk membentuk watak bangsa Indonesia serta membentuk kepribadian manusia Indonesia yang seutuhnya sesuai dengan nilai-nilai yang terkandung dalam sila-sila Pancasila dan UUD 1945.

\section{PENUTUP}

Pendidikan kewarganegaraan pada hakikatnya merupakan pendidikan yang mengarah pada terbentuknya warga negara yang baik dan bertanggung jawab berdasarkan nilai-nilai dan dasar negara Pancasila. Secara konseptualepistemologis, pendidikan Pancasila dapat dilihat sebagai suatu integrated knowledge system.

Bullying merupakan suatu bentuk kekerasan anak yang dilakukan teman sebaya kepada seseorang anak yang lebih rendah atau lebih lemah untuk mendapatkan keuntungan atau kepuasan tertentu. Upaya tindak kekerasan dapat dilakukan melalui pendidikan kewarganegaraan mengajarkan bagaimana menciptakan kerukunan di lingkungan sekola. Sekolah berperilaku proaktif dengan membuat program pengajaran keterampilan social, problemsolving, manajemen konflik, dan penerapan pendidikan pencasila. Guru memantau perubahan sikap dan tingkah laku siswa di dalam maupun di luar kelas shingga perlu adanya kerjasama yang harmonis antara guru BK, guru mata pelajaran serta karyawan sekolah. Sebaiknya orang tua menjalin kerjasama dengan pihak sekolah untuk tercapainya tujuan pendidikan secara maksimal tanpa adanya tindakan bullying antar pelajar di sekolah. Dengan adanya peran antara orang tua siswa dan sekolah dapat meminimalisir tindakan bullying yang terjadi, sehingga proses pertumbuhan anak akan berkembang dengan baik serta menjalini kehidupan yang normal.

\section{DAFTAR PUSTAKA}

Akbar, S. 2011. Revitalisasi Pendidikan Karakter di Sekolah Dasar. Pidato Pengukuhan Guru Besar dalam Bidang Ilmu Pendidikan Dasar pada Fakultas Ilmu Pendidikan (FIP) UM, Malang, Universitas Negeri Malang.

Andersen, L. P., Labrio, M., Andersen, J.H., Lund, T., \& Hansen, C. D. 2015. Bullied at School, Bullied at Work: a Prospective Study. BMC Psychology 3(35):1-15, doi:0.1186/s40359-015-0092-1.

Çubukçu, Z. 2012. The Effect of Hidden Curriculum on Character Education Process of Primary School Students. Educational Sciences: Theory \& Practice, 12 (2):1526- 1534. (Online), (http://files.eric.ed.gov/fulltext/ EJ987859.pdf), diakses pada 24 April 2021.

Ehan. 2013. Bullying dalam Pendidikan.

(Online), (http://file.upi.edu/ Direktori/FIP/JUR._PEND._LU AR_BIASA/19570712198403 2-

EHAN/BULLYING_DALAM_ PENDIDIKAN.pdf), diakses 21 April 2021. 
Hart, C. 2018. Doing a Literature

Bandung:

Universitas Review: Releasing the Research Pendidikan Indonesia. Imagination. SAGE Publication

Hartonian, H. M. 1992. The Social Studies and Project 2061: An Opportunities for Harmony dalam The Social Studies. 83;4:160-163.

Jansen, P.W., Verlinden, M., Berkel, A.D., Mieloo, C., Ende, J., Veenstra, R., Verhulst, F.C., Jansen, W. \& Tiemeier, H. 2012. Prevalence of Bullying and Victimization Among Children in Early Elementary School: Do Family and School Neighbourhood Socioeconomic Status Matter. BMC Public Health 12 (494): 1-10. (Online), (http://www.biomedcentral.com /1471-2458/12/494) diakses pada 26 April 2021.

Putri, Mulia Karunia Vanya. 2021. Hakikat dan Latar Belakang Pentingnya Pendidikan Kewarganegaraan.

Kompas: https://www.kompas.c om/skola/read/2021/02/17/1736

21769/hakikat-dan-latarbelakang-pentingnyapendidikankewarganegaraan?page $=$ all .

Republika.co.id. 2014. Aduan Bullying Tertinggi. (Online), (http://www.republika.co.id), Rabu, 21 April 2021, 13:00 WIB.

Winataputra, U. S. 2001. Jatidiri Pendidikan Kewarganegaraan sebagai Wahana Pendidikan Demokrasi., $\quad$ (Disertasi) 